See discussions, stats, and author profiles for this publication at: https://www.researchgate.net/publication/340717238

\title{
Biogeographic history and diversification patterns in the Irano-Turanian genus Acanthophyllum s.l. (Caryophyllaceae)
}

Article in Plant Biosystems · April 2020

DOI: 10.1080/11263504.2020.1756974

\section{CITATIONS}

4 authors:

(7)

Masoumeh Mahmoudi shamsabad

3 PUBLICATIONS 2 CITATIONS

SEE PROFILE

Mostafa Assadi

Research Institute of Forests and Rangelands

184 PUBLICATIONS 932 CITATIONS

SEE PROFILE
288

Farideh Moharrek

Tarbiat Modares University

20 PUBLICATIONS 269 CITATIONS

SEE PROFILE

Gonzalo Nieto Feliner

Spanish National Research Council

146 PUBLICATIONS 3,046 CITATIONS

SEE PROFILE

Some of the authors of this publication are also working on these related projects:

I am studying molecular phylogeny of the genus Oxytropis DC. (Fabaceae) View project

Phytosociological studies and vegetation mapping in north west of Khorram-Abad, Iran View project 


\section{Plant Biosystems - An International Journal Dealing with all Aspects of Plant Biology \\ Official Journal of the Societa Botanica Italiana}

ISSN: 1126-3504 (Print) 1724-5575 (Online) Journal homepage: https://www.tandfonline.com/loi/tplb20

\section{Biogeographic history and diversification patterns in the Irano-Turanian genus Acanthophyllum s.I. (Caryophyllaceae)}

\section{Masoumeh Mahmoudi Shamsabad, Farideh Moharrek, Mostafa Assadi \& Gonzalo Nieto Feliner}

To cite this article: Masoumeh Mahmoudi Shamsabad, Farideh Moharrek, Mostafa Assadi \& Gonzalo Nieto Feliner (2020): Biogeographic history and diversification patterns in the IranoTuranian genus Acanthophyllum s.I. (Caryophyllaceae), Plant Biosystems - An International Journal Dealing with all Aspects of Plant Biology, DOI: 10.1080/11263504.2020.1756974

To link to this article: https://doi.org/10.1080/11263504.2020.1756974

View supplementary material $\sqsubset \nearrow$

Accepted author version posted online: 17

Apr 2020.

Published online: 13 May 2020.

Submit your article to this journal $₫$

Wll Article views: 20

View related articles $\widetilde{\nearrow}$

View Crossmark data $\widetilde{\nearrow}$ 


\title{
Biogeographic history and diversification patterns in the Irano-Turanian genus Acanthophyllum s.l. (Caryophyllaceae)
}

\author{
Masoumeh Mahmoudi Shamsabad ${ }^{a}$, Farideh Moharrek ${ }^{b}$, Mostafa Assadi $^{c}$ and Gonzalo Nieto Feliner ${ }^{d}$ \\ ${ }^{a}$ Department of Plant Biology, Tarbiat Modares University, Tehran, Iran; bDepartment of Life Sciences, Natural History Museum, London, UK; \\ 'Research Institute of Forests and Rangelands, Agricultural Research Education and Extension Organization (AREEO), Tehran, Iran; ${ }^{\mathrm{d}}$ Real \\ Jardín Botánico, CSIC, Madrid, Spain
}

\begin{abstract}
The Irano-Turanian (IT) floristic region in Asia contains three biodiversity hotspots and has been a source of xerophytic taxa for neighboring regions. Despite its species richness and large territory, the evolutionary history and biogeography of this floristic region is poorly understood. Acanthophyllum, encompassing ca. 70 subshrubby mostly thorny-cushion species, is one of the important components of the steppe and mountain vegetation of this region. In this study, we investigate the tempo and mode of diversification as well as the biogeographic patterns of this genus. The ancestral area analysis suggests that Acanthophyllum originated east of the Zagros Mountains in the Miocene, from where it expanded westwards. A shift in the speciation rate in the late Pliocene (ca. 3.24 Ma) was detected, based on a nrDNA ITS tree, affecting the lineage of the largest section in the genus, Acanthophyllym sect. Oligosperma. Parallelisms with another IT species-rich genera in aspects such as largely coincident ranges and habitats, presence of a thorny-cushion life-form, similar areas reconstructed for their MRCA, and the inference of a shift in speciation in the region suggest common underlying abiotic and biotic factors or even drivers for diversification and speciation in the high elevation dry continental landscape of IT region.
\end{abstract}

\section{ARTICLE HISTORY}

Received 15 June 2019

Accepted 27 March 2020

\section{KEYWORDS}

Evolutionary history; biogeography; Acanthophyllum; IranoTuranian region; speciation rate shift

\section{Introduction}

Plant distributions resulted from a combination of ecological and historical factors, and the arrangement in kingdoms, provinces, and other subdivisions recognized common distribution patterns across plant groups (Takhtajan 1986). These classic floristic divisions have the potential to orient evolutionary studies by suggesting the possible role of past geological, climatic and evolutionary processes (Vilhena and Antonelli 2015). From a phylogenetic perspective, species richness varies dramatically among clades across the tree of life. Evolutionary biology, and in particular biogeography, attempt to understand the causes for these variations over time, across space and along lineages taking into account underlying processes and intervening factors (Gotelli et al. 2009). This is particularly challenging in biotas evolved across spatially complex areas and geologically and climatically dynamic scenarios (Djamali et al. 2012a; Manafzadeh et al. 2017).

The Irano-Turanian (IT) region covers one third of Eurasia across highly fragmented highlands that have in common a continental climate (Djamali et al. 2012a). In this region, one of the largest in the world, species richness and endemism are not evenly distributed, but concentrated mainly along two hotspots sensu (Mittermeier et al. 2005)-the Irano-Anatolian area and the mountains of Central Asia-and the southern and eastern parts of a third one, the Caucasus (Takhtajan 1986; Manafzadeh et al. 2017). Remarkable examples of species-rich groups with high incidence of endemism in the IT region are Acantholimon Boiss. (Plumbaginaceae) with ca. 200 species, Acanthophyllum C.A.Mey. (Caryophyllaceae) with ca. 70, and Dionysia Fenzl (Primulaceae) with ca. 30 species, often exhibiting cushion-like habits (Takhtajan 1986; Djamali et al. 2012b). The IT region has also been considered a source of xerophytic taxa for neighbouring areas and numerous domesticated plants originated here (Diamond 2002; Zohary et al. 2012; Manafzadeh et al. 2014).

Abiotic factors, in particular geology and paleoclimate, are determinant for current plant distribution (Zohary 1973). The roughly synchronous uplift of the Alborz and Zagros Mountains during the middle Miocene likely had a strong impact on the history of the IT floristic region. The Zagros are the largest mountain belt of the region and are part of the Alpine-Himalayan orogenic system. The onset of crustal thickening, caused by the first collision of the Arabian Plate with Eurasia, started about $25 \mathrm{Ma}$, but uplift, deformation and exhumation across the Zagros and throughout the Arabia-Eurasia collision zone took place later, between 15 and $5 \mathrm{Ma}$ (e.g., Mouthereau 2011). The Alborz Mountains in northern Iran are an intra-continental, east-west oriented orogenic belt formed in response to crustal shortening and

CONTACT Gonzalo Nieto Feliner nieto@rjb.csic.es $Q$ Real Jardín Botánico, CSIC, Madrid, 28014 Spain; Masoumeh Mahmoudi Shamsabad (2.mahmoudishamsabad@modares.ac.ir E Department of Plant Biology, Tarbiat Modares University, Tehran, Iran

4 Supplemental data for this article is available online at https://doi.org/10.1080/11263504.2020.1756974.

(C) 2020 Societá Botanica Italiana 
thickening induced by the ongoing Arabia-Eurasia convergence (Meulenkamp and Sissingh 2003). Palaeoclimate impact in the IT region was marked by the gradual trend of global cooling and aridification initiated during the Oligocene and continued in the Pliocene after the interruption by a warmer episode that peaked in the late-middle Miocene climatic optimum (van Dam 2006; Zachos et al. 2008). Regionally, this latter global warm episode was complemented with variations in the amount of aridity due to the uplift of the Iranian plateau (Ballato et al. 2010). The Pleistocene period was also important since climate-driven range shifts might have represented an opportunity for diversification rather than a threat for mountain coldadapted xerophytic elements such as Acanthophyllum and Acantholimon (Bennett and Provan 2008; Djamali et al. 2012a; Manafzadeh et al. 2014; Moharrek et al. 2019).

The evolution of biotas in the IT region remains poorly explored (Manafzadeh et al. 2017) and studying its highly diverse taxa can help to better understand the evolution of biodiversity in this vast and complex area as well as to identify possible internal and external factors triggering strong diversification (Bouchenak-Khelladi et al. 2015). In recent years, a few studies scrutinized the evolution of species-rich IT key elements (e.g., López-Vinyallonga et al. 2009; Djamali et al. 2012b; Pirani et al. 2014; Manafzadeh et al. 2014; Amirahmadi et al. 2016; Moharrek et al. 2017; 2019), but they are insufficient to build a comprehensive picture of the biogeography of the IT region because scenarios are diverse. For instance, the initial diversification of the xerophytic genus Haplophyllum A.Juss. (Rutaceae) in the Central Asian part of the IT region was estimated to have happened in the early Oligocene, followed by its secondary, Mediterranean, diversification in the early Pliocene (Manafzadeh et al. 2014). By contrast, diversification of Cousinia Cass. was estimated to start in the Miocene, ca. 8.7 Ma (López-Vinyallonga et al. 2009). In this genus, allopatric speciation seems to have driven diversification along a complex topography over the Miocene-Pliocene and was also facilitated during Pleistocene glacial periods alternating with isolation during interglacials (Djamali et al. 2012b). Acantholimon probably diversified under the same dynamic allopatric scenario although more recently, ca. 4.1 Ma (Moharrek et al. 2019). The colonization of water-stressed, substrate-poor mountainous habitats, which were abundant in the IT region during the Pleistocene, seems to have been spurred by the evolution of morphological innovations such as the thorny-cushion habit, which was associated to accelerated diversification rates in this genus. Such a habit could have also facilitated the colonization of IT highlands and diversification of other groups (Boucher et al. 2016), including Acanthophyllum (Ghaffari 2004; Mahmoudi Shamsabad et al. 2018).

Acanthophyllum, an IT element encompassing ca. 70 subshrubby species many of them being thorny cushions, inhabits areas between Syria and western China (Schiman-Czeika 1988; Ghaffari 2004; Mahmoudi Shamsabad et al. 2018) but is mostly concentrated in northeastern Iran and adjacent regions in Afghanistan and Turkmenistan. Fifty-six species of Acanthophyllum s.s. occur in the territory covered by Flora
Iranica (Schiman-Czeika 1988), i.e., Iran, Afghanistan and adjacent territories of Turkmenistan, Azerbaijan, Pakistan and Iraq. Acanthophyllum species grow on exposed habitats on sandy or stony hills and rocky slopes. The available karyological information reports three ploidy levels (Ghaffari 2004). Most species in Acanthophyllum sections Oligosperma and Macrostegia are diploid $(2 \mathrm{n}=2 \mathrm{x}=30)$, but $A$. caespitosum exhibits a different number $(2 n=2 x=28)$ together with a distinct inflorescence morphology. The species in sect. Acanthophyllum are tetraploid $(2 \mathrm{n}=4 \mathrm{x}=60)$ and distributed in central and western parts of the IT region. The hexaploid level $(2 n=6 x=90)$ is found in sect. Pleiosperma consisting of species distributed in eastern and northern parts of the IT region (Ghaffari 2004).

Molecular phylogenetic studies revealed that three small genera-Allochrusa Bunge, Ochotonophila Gilli and Scleranthopsis Rech.f.-as well as three out of four species analysed of another one, Diaphanoptera Rech.f., and Gypsophila cerastoides D.Don are all nested within Acanthophyllum, and that its diversification started ca. 11.1 Ma (Pirani et al. 2014). We here follow such an enlarged circumscription of the genus and refer to it as Acanthophyllum s.l.

We assembled datasets with published sequences of the internal transcribed spacers of the nuclear ribosomal DNA (ITS) and the intron of the plastid gene rps16 for $75 \%$ of the Acanthophyllum s.l. species, to investigate the tempo and mode of diversification and reconstruct the spatiotemporal evolution of this genus. Specifically, we aimed to (1) estimate the age of divergence of major lineages within Acanthophyllum s.l. using relaxed molecular clocks and two different calibration strategies; (2) infer changes in diversification rates in the evolutionary history of Acanthophyllum s.l. over time and across clades; 3 ) reconstruct the biogeographic pathways by which this genus reached its current range.

\section{Materials and methods}

\section{Taxon sampling, nucleotide matrix data assembly and model selection}

A two-marker dataset (ITS and rps16) for 52 Acanthophyllum s.l. taxa was obtained from previously published sequences deposited in GenBank, most of them from Pirani et al. (2014) but also three from Mahmoudi Shamsabad et al. (2019): 46 species of Acanthophyllum s.s., four of Diaphanoptera, two of Allochrusa, one of Ochotonophila, one of Scleranthopsis and one of Gypsophila (G. cerastioides). Samples from these five genera have not been here included in Acanthophyllum despite the phylogenetic results in Pirani et al. (2014) since a comprehensive taxonomic review of Acanthophyllum s.l. would be required before the taxonomic changes are made. In addition, Diaphanoptera afghanica Podlech did not fall within Acanthophyllum clade in such study. Fifteen other Caryophyllaceae were included as outgroups: Cerastium arvense L. and Holosteum umbellatum L. from tribe Alsineae, Gypsophila repens L., G. elegans M.Bieb., Saponaria officinalis L. and S. ocymoides L. from tribe Caryophylleae, Drypis spinosa L. from tribe Sagineae, Minuartia laricifolia (L.) Schinz \& Thell. from tribe Sclerantheae, Lychnis coronaria (L.) Desr., 
Silene italica (L.) Pers., S. campanula Pers. and S. rothmaleri P. Silva from tribe Sileneae, Minuartia geniculata (Poir.) Thell., Spergula arvensis L. and Spergularia marina (L.) Besser from tribe Sperguleae. Tribe adscription follows Harbaugh et al. (2010).

We created three datasets: (1) ITS comprising 73 terminals; (2) rps 16 with 62 terminals; and (3) a combined dataset comprising 52 terminals. The sampling encompasses the major distribution areas of Acanthophyllum in the IT region, including its main diversity center in Iran and Afghanistan, as well as Anatolia and Pakistan. All samples, along with locality data, voucher information, and GenBank accession numbers are listed in Supplementary Appendix S1.

The nucleotide sequences were aligned using Muscle (Edgar 2004) followed by manual adjustment implemented in MEGA version 7.0 (Kumar et al. 2016) and then refined by visual inspection. The best substitution model identified by jModeltest 2.1.7 (Darriba et al. 2012) was GTR $+G$ model for both markers.

\section{Divergence time estimation}

Divergence times were inferred with BEAST v1.8.0 (Drummond et al. 2012), ran at the CIPRES Science Gateway (http://www. phylo.org/; Miller et al. 2010) assuming a Bayesian relaxed molecular clock. The dated Bayesian analyses followed two different approaches: First, a node dating approach was applied to the individual markers and to the combined data set. The trees were calibrated using the age of a described fossil inflorescence from the Middle-Late Eocene (Jordan and Macphail 2003). Following a detailed phylogenetic study (Jordan and Macphail 2003), this fossil was placed within or as sister to subfamilies Alsinoideae and Caryophylloideae (Frajman et al. 2009). Given the uncertainty regarding the positioning of the fossil with respect to these subfamilies, we chose the most conservative approach (the one that produces the oldest ages) and applied an age constraint at the crown node of Alsinoideae and Caryophylloideae. We calibrated the root node of our trees using a lognormal distribution prior with offset $=$ 33.9 Ma, and SD = $1 \mathrm{Ma}$, covering the entire Middle-Late Eocene geological interval (33.9-47.8 Ma). A general time reversible model with rate variation across sites, modeled using a gamma distribution $(\mathrm{GTR}+\mathrm{G})$, was applied to each data matrix.

The second approach consisted in a multispecies coalescent model implemented in *BEAST (Drummond and Rambaut 2007; Drummond et al. 2012) to estimate the species tree for 52 species of Acanthophyllum s.l. To convert genetic branch lengths into absolute times, we used published ITS and plastid substitution rates following the procedures in Pirani et al. (2014). The data matrix was composed of the ITS and the rps16 unlinked partitions and a GTR + G substitution model was applied for both. The prior probability of the clock rate was set to a truncated normal distribution with a mean of $2.15 \times 10^{-9}$, ranging from $0.38 \times 10^{-9}$ to $7.83 \times 10^{-9}$ mutations per site per year for ITS estimated for perennial woody plants (Kay et al. 2006), and a truncated normal distribution with a mean of $0.67 \times 10^{-3}$, ranging from
$0.5 \times 10^{-4}$ to $2.6 \times 10^{-3}$ substitutions per site per million years for rps16. For the rps16, we provided rate priors by dividing the lower and upper rates of ITS by three (following the typical magnitudes for plastid substitution rates compared to nuclear rates in plants; Wolfe et al. 1987; Gaut et al. 1996; Yue et al. 2010). This was done to speed up convergence (particularly by excluding highly suboptimal starting rates). The rps16 prior standard deviation was set to $0.7 \times 10^{-3}$, which fits in the truncated normal distribution, is larger than the mean and unlikely to bias its posterior estimate. The estimated rates were checked and modified to the values that allowed the rps 16 posteriors to be able to fluctuate within these priors. The ploidy level for rps16 was set to haploid. For comparison this approach was also applied to the individual datasets.

In the tree dating analyses, molecular rates were allowed to vary among lineages around an average value, by enforcing an uncorrelated relaxed lognormal clock of evolutionary rates. A birth-death branch process prior was used. The MCMC chain was run in two separate analyses for 50 million generations sampling every $1000^{\text {th }}$ generation. LogCombiner v1.7.5 (Drummond et al. 2012) was used to combine the log and tree files after discarding the initial 5 million iterations of each analysis as burn-in. Tracer v1.6 (Rambaut and Drummond 2013) was used to assess that Effective Sample Sizes (ESS) were above 200 for optimal convergence and tree likelihood stationarity. Tracer automatically removed the first $10 \%$ of the log statistics from the combined sample, so we correspondingly discarded the first $10 \%$ of trees. A maximum clade credibility (MCC) tree was constructed with TreeAnnotator v.1.7.5 (Drummond et al. 2012), depicting the maximum sum of posterior clade probabilities (nexus file in Supplementary Appendix S2), and visualized in FigTree v1.4.4 (Rambaut 2018).

\section{Ancestral area reconstruction analyses}

The biogeographic history of Acanthophyllum was explored using dispersal-extinction-cladogenesis (DEC) method (Ree and Smith 2008) implemented in RASP (Reconstruct Ancestral State in Phylogenies) v. 3.2 (Yu et al. 2015). This method has been widely used to study the biogeographic patterns in closely related taxa with restricted geographic ranges. Also, DEC method allows estimating the probability of ancestral areas at each node of a phylogenetic tree and assumes extinction or dispersal by contraction or expansion of the ancestral geographic range, respectively (Ree and Smith 2008). Several IT species (including Silene goniocaula Boiss., Cousinia lasiolepis Boiss., Primula capitellata Boiss., Pedicularis cabulica Benth., Gagea capillifolia Vved. ex Czerniak.) currently display disjunct west-east distribution patterns in the alpine zones of Asian mountain chains: between the Zagros, in the west, and either the mountains of Afghanistan or the west Himalayas and central Asia, in the east (Noroozi et al. 2008; Manafzadeh et al. 2017). However, this is not the case in Acanthophyllum since most species are concentrated in northeastern Iran and adjacent regions in Afghanistan and Turkmenistan, and species richness severely 
decreases both from eastern Afghanistan to China and from western Iran to Turkey to and Syria (Supplementary Figure S1) (Ghaffari 2004; Mahmoudi Shamsabad et al. 2012). Therefore, in defining the boundaries and number of our operational areas, we considered the current distribution patterns of Acanthophyllum s.l. species, i.e., geographic areas defined by the congruent distribution of two or more species. We noted a pattern of species occurring east but not west of the chain and vice versa as well as a sharp decline in number of species west of Iran and east of Afghanistan. This is consistent with the different climatic conditions east and west of the Zagros Moutains since this chain blocks the moist air masses from entering in the interior parts of Iran (Alijani 2008). Accordingly, the range of Acanthophyllum was divided into two areas, the regions west (A) and east (B) of the Zagros Mountains (Figure 1). To avoid biases related to incomplete taxon sampling in the outgroup, we pruned the BEAST MCC trees by removing outgroups and leaving only 52 terminals of Acanthophyllum s.l.

\section{Diversification analyses}

To understand the diversification dynamics of Acanthophyllim s.l., we used the Bayesian Analysis of Macroevolutionary Mixtures program (BAMM) (Rabosky 2014), which estimates diversification rate through time and identifies shifts in diversification rate. This method employs MCMC and Bayes Factor comparisons as well as Compound Poisson Process (CPP) models to explore alternative diversification dynamic regimes, allowing for both rate-heterogeneity across lineages and variation in speciation rates over time. As for ancestral area reconstruction analyses, we removed all outgroup taxa. To account for incomplete taxon sampling, we specified a global sampling probability of 0.75 . Priors for BAMM were generated using setBAMMpriors function in BAMMtools package based on the MCC tree (Rabosky et al. 2014). It has been suggested that the likelihood function of BAMM might be incorrect and that the program suffers from strong prior sensitivity and unreliable rate estimates (Moore et al. 2016). However, Rabosky et al. (2017) recently reported that they were unable to reproduce the prior sensitivity and that the shortcomings indicated by Moore et al. (2016) were likely due to a misapplication of the program and poorly designed test data. Sensitivity to the choice of the CPP prior, which informs the expected number of rate shifts, was assessed by performing multiple BAMM analyses with varying CPP priors $(1,5$, and 10). We ran the analyses for 5 million generations, sampling every $5000^{\text {th }}$ generation. Since priors had little effect on the results, we ran the final analysis with the priors estimated by BAMMtools and four independent chains of 10 million generations each, sampled every $10,000^{\text {th }}$ generation. The convergence of MCMC was assessed using the coda package in R (Plummer et al. 2006) by computing the effective sample sizes (ESS) of log likelihoods. An ESS value above 200 was considered to reach convergence and the first $10 \%$ sampling data was then discarded as burn-in. The posterior distribution was used to summarize and visualize diversification rates over the branches of the phylogeny and through evolutionary time. Results were analyzed and plotted using the BAMMtools package (Rabosky et al. 2014).

\section{Results}

\section{Divergence time and ancestral area reconstruction}

The three datasets yielded overall similar topologies for the main clades, but there were incongruences affecting some genera and species within those clades. For instance, the clade formed by Allochrusa bungei Boiss. and A. versicolor Boiss. is sister to the remainder of Clade II in the ITS and combined trees (Figure 2A, Supplementary Figure $S 2 A, B, D$ ) but nested in it in the rps16 trees (Figure 2B, Supplementary Figure S2C). Two other dissimilarities affecting positions of the close genera in Clade I are Ochotonophila allochrusoides Gilli and Scleranthopsis aphanantha (Rech.f.) Rech.f. Phylogenetic relationships within the Acanthophyllum s.l. clade recovered in the present study largely agree with those inferred by Pirani et al. (2014), including the two main clades I and II (Figures 1 and 2), and thus here we do not focus on topological aspects. Divergence times and HPD intervals for Acanthophyllum s.l. clade obtained with the two calibration approaches for the three datasets (Figure 2 and Supplementary Figure S2) are summarized in Table 1. Estimated average divergence times for the crown node of Acanthophyllum s.l. ranged from 9.44 to $14.29 \mathrm{Ma}$, whereas those for the crown nodes of clade I and clade II ranged from 6.47 to $12.9 \mathrm{Ma}$ and from 3.18 to $9.1 \mathrm{Ma}$, respectively. HPD intervals also showed considerable variation across datasets and Bayesian approach: from 4.75 to 21.7 myr for the crown node of Acanthophyllum s.l., 4.39 to 18.9 myr for the crown nodes of clade I, and 3.4 to 16.6 myr for the crown nodes of clade II. Unlike the average divergence times, for the amplitude of the HPD intervals there is a noticeable pattern such that the combined datasets produced the larger intervals than the individual datasets (Table 1).

In the ancestral area reconstruction, the eastern Iran-Afghanistan region (area B) was inferred to be the most likely ancestral area of Acanthophyllum s.l., as well as of the clade I (Figure 1). The ancestral area of the MRCA of the clade II was widespread in western Iran and eastern Iran-Afghanistan (areas $A B$ ), implying a dispersal event to the west. Furthermore, there is a strong geographic concordance for these two clades since a majority of the species occurring east and west of the Zagros Moutains fell in separate clades (Figure 1). Specifically, of the 52 species sampled of Acanthophyllum s.l., 42 consistently occur in area A and were positioned in clade II or occur in area B and belong to clade I. Of the remaining species, nine occur in both areas and were positioned either in clade I or in clade II (6 and 3, respectively). The only discordant pattern is represented by $A$. sordidum Bunge ex Boiss., which occurs in area $B$ but belongs to clade II.

\section{Diversification rates}

In the BAMM analyses, we confirmed convergence of the MCMC chains after discarding the burn-in and that effective 

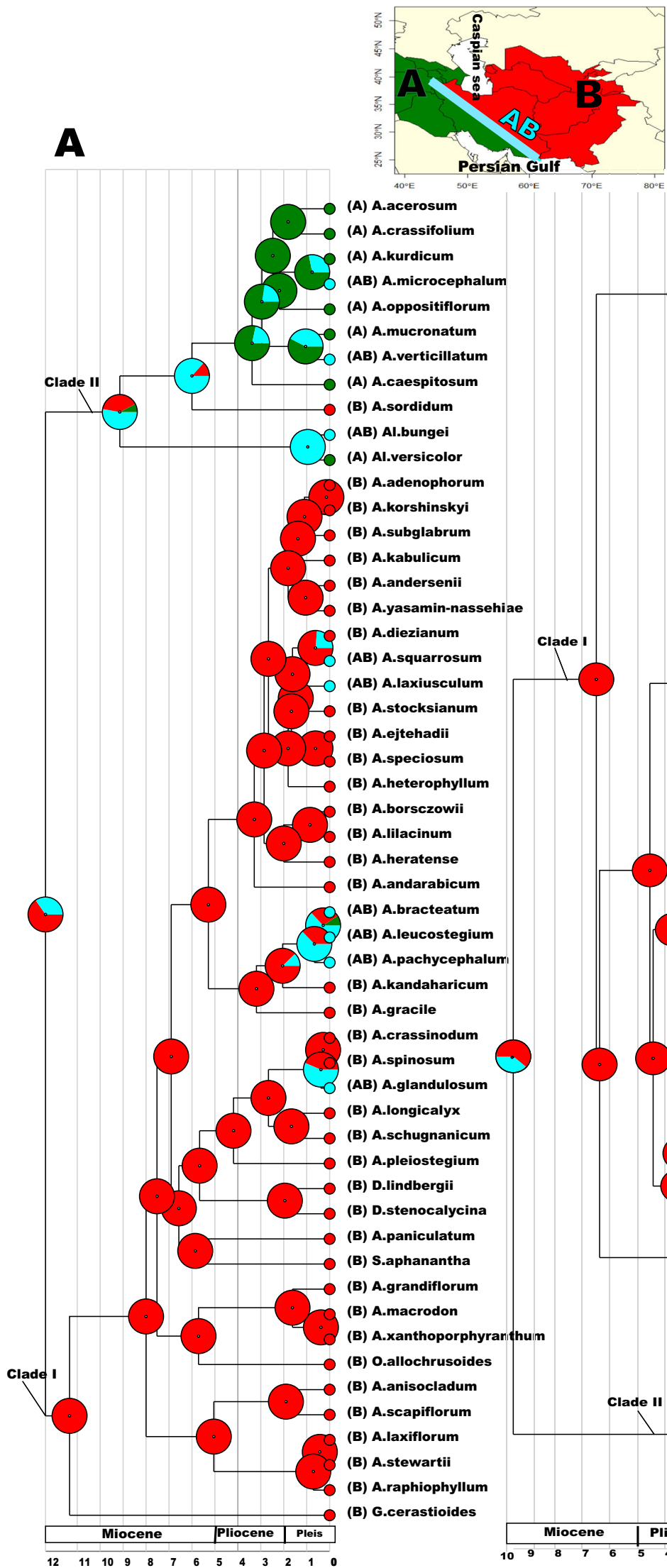

B

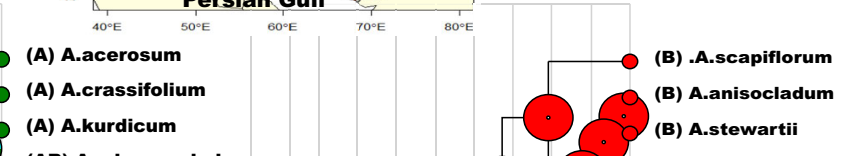

(AB) A.microcephalum

(A) A.oppositiflorum

(A) A.mucronatum

(AB) A.verticillatum

(A) A.caespitosum

(B) A.sordidum

(AB) Al.bungei

(A) Al.versicolor

(B) A.adenophorum

(B) A.korshinskyi

(B) A.subglabrum

(B) A.kabulicum

(B) A.andersenii

(B) A.yasamin-nassehiae

(B) A.diezianum

(AB) A.squarrosum

(AB) A.laxiusculum

(B) A.stocksianum

(B) A.ejtehadii

(B) A.speciosum

(B) A.heterophyllum

(B) A.borsczowii

(B) A.lilacinum

(B) A.heratense

(B) A.andarabicum

(AB) A.bracteatum

(AB) A.leucostegium

(AB) A.pachycephalum

(B) A.kandaharicum

(B) A.gracile

(B) A.crassinodum

(B) A.spinosum

(AB) A.glandulosum

(B) A.longicalyx

(B) A.schugnanicum

(B) A.pleiostegium

(B) D.lindbergii

(B) D.stenocalycina

(B) A.paniculatum

(B) S.aphanantha

(B) A.grandiflorum

(B) A.macrodon

(B) A.xanthoporphyranthum

(B) O.allochrusoides

(B) A.anisocladum

(B) A.scapiflorum

(B) A.laxiflorum

(B) A.stewartii

(B) A.raphiophyllum

(B) G.cerastioides

$\begin{array}{lllllllllllll}12 & 11 & 10 & 9 & 8 & 7 & 6 & 5 & 4 & 3 & 2 & 1 & 0\end{array}$

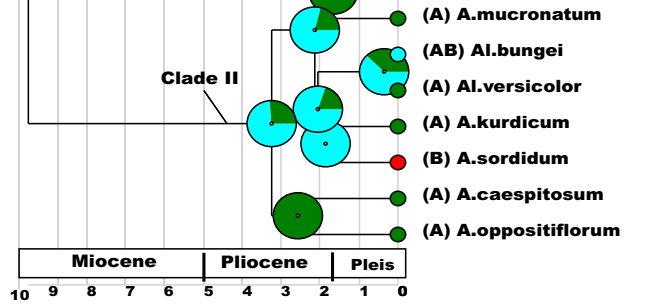

Figure 1. Ancestral Area Reconstruction of Acanthophyllum s.I. using (A) ITS and (B) rps 16 datasets. Current genus distribution has been divided into two areas for analysis indicated by color-codes: regions west (A) and east (B) of the Zagros Mountains. Current species distribution in the two areas is indicated by color-coded circles on the tree tips, and pie charts at nodes represent alternative range probabilities. 

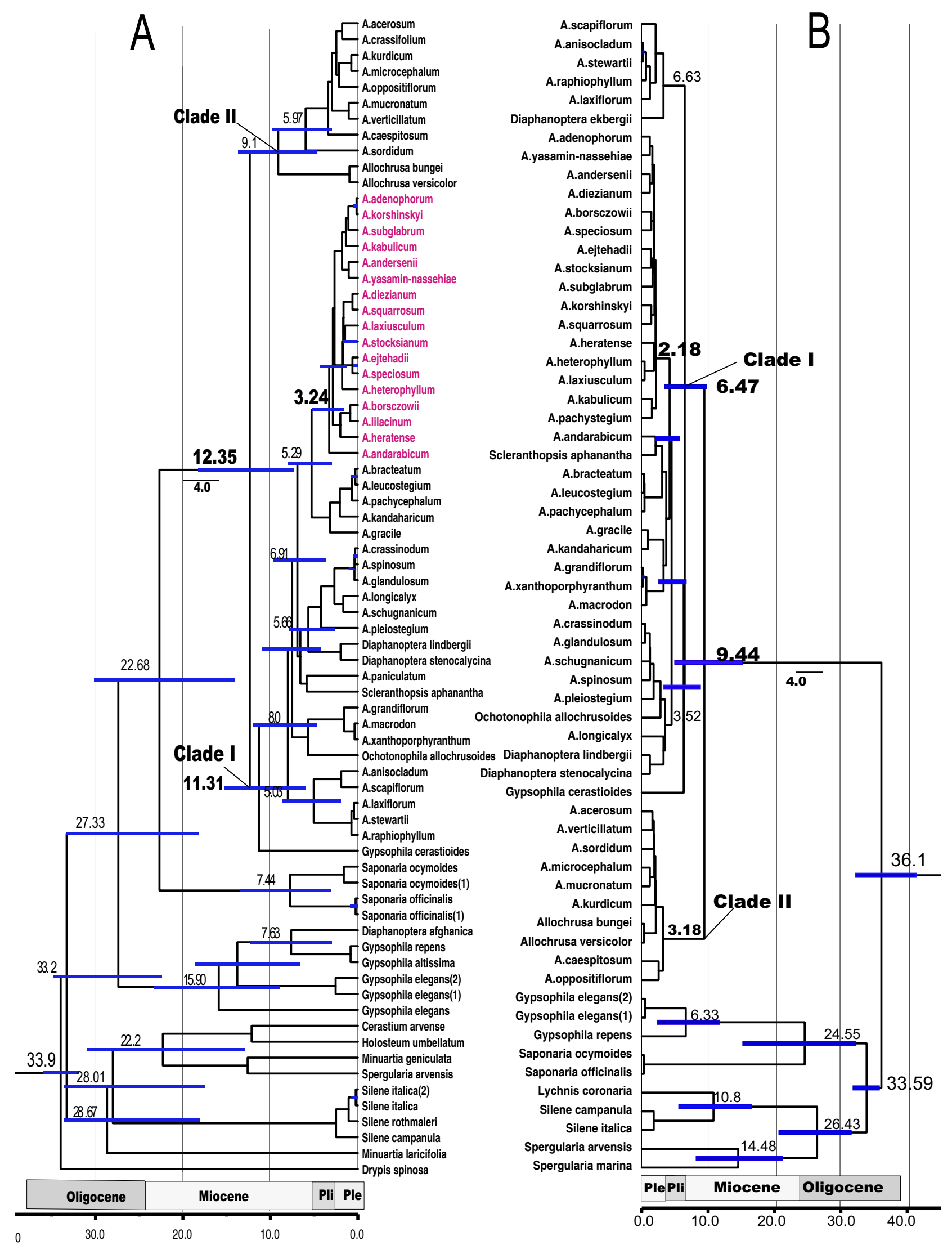

Figure 2. Phylogenetic relationships within Acanthophyllum s.l. based on (A) ITS and (B) rps 16, inferred with BEAST. Chronograms represent the maximum clade credibility trees estimated using a fossil calibrated approach, with mean divergence times in million years ago shown for important nodes. Blue bars represent $95 \%$ highest posterior densities for node ages. Species in Acanthophyllum sect. Oligosperma (excluding A. caespitosum; see text) are marked in red. 
sample sizes were $>900$ for both the number of shifts and log likelihoods. The results supported a diversity-dependent speciation process across Acanthophyllum s.l. with a net diversification rate $r=0.30$ species $/ \mathrm{Ma} \quad(95 \%$ quantile $=$ $0.01-0.42$ ), speciation rate $\lambda=0.51$ species/Ma (95\% quantile $=0.28-0.62)$, and extinction rate $\mu=0.21$ species $/ \mathrm{Ma}(95 \%$ quantile $=0.01-0.44)$ for the ITS dataset. The rps16 dataset resulted in a net diversification rate $r=0.29$ species $/ \mathrm{Ma}(95 \%$ quantile $=0.02-0.43$ ), speciation rate $\lambda=0.50$ species $/ \mathrm{Ma}$ (95\% quantile $=0.21-0.65$ ), and extinction rate $\mu=0.21$ species $/ \mathrm{Ma}$ (95\% quantile $=0.01-0.44$ ).

For the ITS dataset, the $95 \%$ credible set of rate shift configurations sampled with BAMM included four distinct ones; the configuration with the highest probability (0.95) exhibited one shift in sect. Oligosperma (except for A. caespitosum Boiss.) within clade II (Figures 1 and 2). Rate-through-time plots showed that there are relatively accelerated speciation and diversification rates and a flat extinction rate using the ITS dataset (Figure 3).

The rps16 dataset did not show any significant shift (Figure 3) and the rate-through-time plots of speciation, extinction and diversification remained almost flat across the evolutionary history of Acanthophyllum s.l. for this marker (Figure 3).

\section{Discussion}

\section{Divergence times and biogeography}

Divergence time estimates within Acanthophyllum s.l. vary across datasets-based on independent or concatenated markers - and Bayesian approaches, i.e., root node fossil calibrated vs. relaxed clock model using published substitution rates implemented in *BEAST, also when compared to Pirani et al. (2014) (Table 1; Figure 2 and Supplementary Figure S2). Under the first approach, there is a sharp contrast between the dates based on the ITS and combined data sets, which are close to each other and higher than those based on the plastid region. Under the second approach, estimates based on the ITS and combined data sets are also close to each other. However, unlike the first approach, the estimated date based on the rps 16 dataset is older than those based on the ITS and combined datasets both for the crown nodes of Acanthophyllum s.l. and clade I (Table 1). The divergence time for the split of the lineages leading to Acanthophyllum sordidum and Allochrusa versicolor estimated in Frajman et al. (2009) using the same fossil for node calibration of a matk dataset of Caryophyllaceae, $2.8 \mathrm{Ma}$, is consistent with those found here in the fossil-calibrated rps16 dataset (Figure 2B), but not with the ITS or concatenated datasets, where it is much older (Figure 2A and Supplementary Figure S2D). The pattern found regarding the amplitude of the HPD intervals (Table 1), which is consistently wider in the trees resulting from a combined data set, also holds when compared to those intervals reported in Pirani et al. (2014). The HPD intervals in the latter study, based on a combined dataset, are even wider than those found here and span the Oligocene, Miocene and Pliocene. The likely explanation for such a pattern is that topological differences (and thus phylogenetic signal) between the ITS and plastid trees increase the uncertainty and thus the amplitude of the confidence intervals. Since the multispecies coalescence approaches, such as *BEAST, account for different coalescence times for the genes, but not for other causes such as hybridization, the different topological position of Allochrusa bungei, A. versicolor, Ochotonophila allochrusoides and Scleranthopsis aphanantha in the ITS and combined dataset (Figure 2A, Supplementary Figure $S 2 A, B, D$ ) vs. the rps 16 trees (Figure 2B, Supplementary Figure $\mathrm{S} 2 \mathrm{C}$ ) may be due to hybridization. However, the short branches in the rps 16 topology recommend caution and further analyses based on a larger representation of the genome.

If we focus on the results of the ITS tree from the fossilcalibrated approach, which is based on more informative characters than the rps16 but carries less uncertainty than the two regions concatenated, and has a specific calibration scheme for this group compared to the second approach that is based on published rates, we can propose the following scenario (Figure 2A). Acanthophyllum s.l. seem to have diverged from its sister group during the early Miocene and started to diversify sometime during the late Miocene. Such a timing is consistent with the idea that the uplift of the Alborz and Zagros Moutains, which occurred along that period, might have promoted high levels of alpine endemism in this area (Noroozi et al. 2008, 2019; Pirani et al 2014; Moharrek et al. 2019).

The biogeographic analysis suggests that Acanthophyllum s.l. as well as clade I most likely originated in eastern Iran-Afghanistan (area B) (Figure 1). This possibility is consistent with the fact that the Khorassan-Kopet Dagh floristic province in NE Iran and neighboring Afghanistan and Turkmenistan is the major center of taxonomic diversity of the genus. The reconstructed ancestral area for clade II, supported by both ITS and rps 16 analyses, spanned across western Iran and eastern Iran-Afghanistan (areas A and B). We suggest that easterly adjacent Syria and westerly adjacent Western China were colonized by westward and eastward dispersal events, followed by peripatric speciation. This scenario, including the origin in eastern Iran-Afghanistan was also reported for other IT xerophyte taxa such as Acantholimon (Moharrek et al. 2019) and is consistent with a pattern of xerophytes migration from east to west (Manafzadeh et al. 2014).

Clade II is far less species-rich than the Clade I and includes the only clear exception to the concordance between phylogenetic placement and geographic distribution: A. sordidum (Ghaffari 2004; Pirani et al. 2014, 2019). Of the five species here sampled belonging to Acanthophyllum section Pleiosperma, only $A$. sordidum is placed in clade II whereas A. crassinodum Yukhan. \& J.R.Edm., A. glandulosum Bunge ex Boiss., A. schugnanicum Schischk. and A. spinosum C.A.Mey are placed in clade I. The first two of these four species have been reported as hexaploids whereas $A$. sordidum is tetraploid (Ghaffari 2004). Although this raises the possibility that $A$. sordidum might have been involved in an allopolyploid event-with diploids from section Oligosperma from clade I-to give rise to hexaploids in sect. Pleiosperma, the 

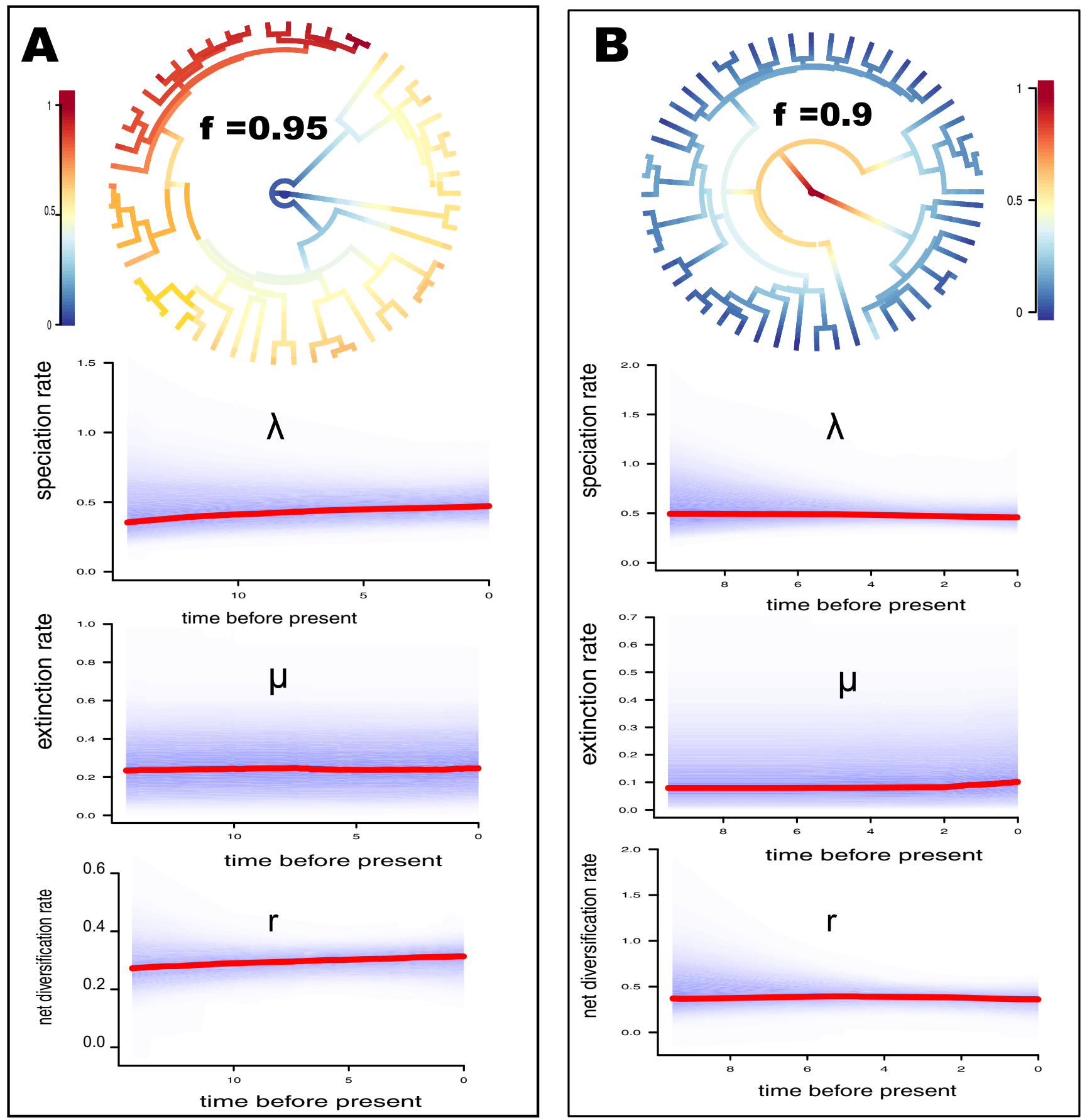

Figure 3. Diversification rate shifts within Acanthophyllum s.l. through time. (A) Rate shift configuration with the highest posterior probability model showing one significant rate shift in speciation $(\lambda)$ - color coded by $\lambda$-, rates-through-time analysis of speciation $(\lambda)$, extinction $(\mu)$ and net diversification $(r)$ in Acanthophyllum s.l. using nrDNA ITS. (B) Rate shift configuration with the highest posterior probability model showing no significant rate shift in rps 16 dataset. rates-through-time analysis of speciation $(\lambda)$, extinction $(\mu)$ and net diversification $(r)$ in Acanthophyllum s.l. using rps 16 datset.

consistent nuclear and plastid affinities of those four species within clade I do not support such a merger. To support such hypothesis we would have to assume that signal of $A$. sordidum was lost in sect. Pleiosperma via concerted evolution in the ITS (Feliner and Rosselló 2012) and/or via plastid capture if $A$. sordidum contributed to such hypothetical allopolyploid event as ovule donor (Tsitrone et al. 2003). The alternative is that the traditional placement of $A$. sordidum in sect. Pleiosperma based on some morphological characters (Schiman-Czeika 1988) is simply wrong and their relationships are distant as phylogenetic evidence suggests. Our biogeographic and diversification results are compatible with both hypotheses and thus a more thorough sampling including chromosome numbers is needed.

\section{Diversification of Irano-Turanian mountain xerophytes}

Scenarios with one (ITS) or zero (rps16) shifts in macroevolutionary rate regimes were inferred most frequently by our diversification analyses (Figure 3). The scenario with one shift suggests an increase in speciation rates in section 
Oligosperma, comprising part of clade I, around 3.24 Ma in the Pliocene. This is the largest section in Acanthophyllum including more than 20 species, of which 17 have been sampled in this study. The incidence of such increase in speciation rate leading to a rapid formation of species with close and overlapping ranges is consistent with the species' identification problems in this section (Mahmoudi Shamsabad et al. 2019). The fact that no shift was identified by rps 16 and that the speciation rate inferred with this marker is relatively flat could suggest that a species under-sampling effect on this clade had biased the shift position in BAMM analyses in the ITS tree. However, BAMM takes into account possible species under-sampling effects (see material and methods section), and $75 \%$ of the species of this clade included in our analyses do not represent a significant under-sampling. We thus suggest that the absence of the shift in the plastid tree is due to different evolutionary rates in ITS and plastid regions, which is in accordance with the lower number of informative characters and the low sequence divergence values between the plastid sequences (Pirani et al. 2014).

Our results suggest that during the late Miocene, Acanthophyllum s.l., experienced a relatively high speciation rate and the evolution of the cushion-thorny habit may have spurred such increase in speciation rates. Interestingly, a strikingly similar morphological syndrome including life form and leaves is exhibited by another IT genus, Acantholimon (Plumbaginaceae), occurring in similar habitats (Moharrek et al. 2019). The interesting parallelism between the two genera goes beyond their morphological adaptations to the same habitats. They have similar distribution ranges although that of Acantholimon is larger (Rechinger and Schiman-Czeika 1974). The reconstructed ancestral area for both is Eastern Iran-Afghanistan (Moharrek et al. 2019). Both genera experienced shifts in diversification although in Acantholimon there were two shifts associated with the evolution of the cushionthorny habit whereas in Acanthophyllum this habit is predominant also outside the lineage that experienced the shift (A. sect. Oligosperma). In addition, both genera required enlarging their taxonomic circumscription to accommodate their phylogenetic history, which is probably due to disparate evolution rates in different morphological charactersaffected directly or not by the diversification shifts-which obscure the existing synapomorphies used to define large clades.

Such similarities in genera from two separate families suggest common environmental underlying factors playing an important role in their diversification. Based on the habitats where species of both genera mostly occur, it is likely that water-stressed, substrate-poor mountainous habitats-such as stony mountain slopes or summit areas with poorly developed soils, or even rocky outcrops-exerted strong selection pressures, in addition to grazing. We thus hypothesize that the acquisition of the cushion-thorny habit facilitated the colonization of vast territories of seemingly homogeneous continental high elevation environments and spurred diversification. These environments where Acanthophyllum and Acantholimon species occur are frequent and even dominant in the IT region, and host also other species-rich genera, such as Astragalus L., Cousinia, Haplophyllum, Onobrychis Mill. (Podlech and Maassoumi 2003; Ranjbar and Karamian 2003; López-Vinyallonga et al. 2009; Djamali et al. 2012b; Manafzadeh et al. 2014; Pirani et al. 2014; Amirahmadi et al. 2016). This scenario is consistent with three additional facts: (1) nearly three quarters of the endemic species in Iran are restricted to mountain ranges and the rate of endemism increases along an elevational gradient (Noroozi et al. 2019); (2) in the niche model of Acanthophyllum squarrosum cold and dry environments are determinant for increasing habitat suitability (Mahmoudi Shamsabad et al. 2018); (3) both cold and dry environments are the drivers of repeated evolution of the cushion life form in general and Caryophyllaceae is the family having the highest number of cushion species (Boucher et al. 2016).

To further refine the historical scenarios for Acanthophyllum s.l. and other IT-rich groups, methods for projecting ancestral ecological niches onto palaeogeographical configurations need to be improved and implemented (Crisp and Cook 2012). Within Acanthophyllum s.l., the application of niche modelling tools to a wide sample of species will be useful to better explain the relative roles of geological versus climatic factors in speciation processes, and of niche conservatism versus niche evolution in shaping distributional patterns in the IT region. A more thorough representation of the genus in molecular- and karyological-based studies, including intraspecific sampling, would also be helpful particularly for taxa with conflicting positions in the inferred phylogenies. In addition, new molecular data, preferably covering a wide genomic representation, is necessary for exploring the incongruences between the nuclear and plastid trees.

\section{Acknowledgments}

We thank Firouzeh Bordbar and an anonymous reviewer for helpful comments on the earlier versions of the manuscript.

\section{Disclosure statement}

No potential conflict of interest was reported by the authors.

\section{Funding}

This study was supported by the grant CGL2017-88500-P (AEI/FEDER, EU) to GNF from the Spanish Ministry of Economy and Competitivity.

\section{References}

Alijani B. 2008. Effect of the Zagros Mountains on the spatial distribution of precipitation. J Mt Sci. 5(3):218-223.

Amirahmadi A, Kazempour-Osaloo S, Kaveh A, Maassoumi AA, Naderi R. 2016. The phylogeny and new classification of the genus Onobrychis (Fabaceae-Hedysareae): evidence from molecular data. Plant Syst Evol. 302(10):1445-1456.

Ballato P, Mulch A, Landgraf A, Strecker MR, Dalconi MC, Friedrich A, Tabatabaei SH. 2010. Middle to late Miocene Middle Eastern climate from stable oxygen and carbon isotope data, southern Alborz mountains, N Iran. Earth Planet Sci Lett. 300(1-2):125-138. 
Bennett KD, Provan J. 2008. What do we mean by "refugia"?. Quat Sci Rev. 27(27-28):2449-2455.

Boucher FC, Lavergne S, Basile M, Choler P, Aubert S. 2016. Evolution and biogeography of the cushion life form in angiosperms. Perspect Plant Ecol Evol Syst. 20:22-31.

Bouchenak-Khelladi Y, Onstein RE, Xing Y, Schwery O, Linder HP. 2015. On the complexity of triggering evolutionary radiations. New Phytol. 207(2):313-326.

Crisp MD, Cook LG. 2012. Phylogenetic niche conservatism: what are the underlying evolutionary and ecological causes? New Phytol. 196(3): 681-694.

Darriba D, Taboada GL, Doallo R, Posada D. 2012. JModelTest 2: more models, new heuristics and parallel computing. Nat Methods. 9(8): 772-772.

Diamond J. 2002. Evolution, consequences and future of plant and animal domestication. Nature. 418(6898):700-707.

Djamali M, Baumel A, Brewer S, Jackson ST, Kadereit JW, LópezVinyallonga S, Mehregan I, Shabanian E, Simakova A. 2012b. Ecological implications of Cousinia Cass. (Asteraceae) persistence through the last two glacial-interglacial cycles in the continental Middle East for the Irano-Turanian flora. Rev Palaeobot Palynol. 172: 10-20.

Djamali M, Brewer S, Breckle SW, Jackson ST. 2012a. Climatic determinism in phytogeographic regionalization: a test from the IranoTuranian region, SW and Central Asia. Flora Morphol Distrib Funct Ecol Plants. 207(4):237-249.

Drummond AJ, Rambaut A. 2007. BEAST: Bayesian evolutionary analysis by sampling trees. BMC Evol Biol. 7(1):214.

Drummond AJ, Suchard MA, Xie D, Rambaut A. 2012. Bayesian phylogenetics with BEAUti and the BEAST 1.7. Mol Biol Evol. 29(8):1969-1973.

Edgar RC. 2004. MUSCLE: multiple sequence alignment with high accuracy and high throughput. Nucleic Acids Res. 32(5):1792-1797.

Feliner GN, Rosselló JA. 2012. Concerted evolution of multigene families and homoeologous recombination. In: Wendel JF, Greilhuber J, Doležel J, Leitch I, editors. Plant genome diversity, vol 1, plant genomes, their residents and, and their evolutionary dynamics. Wien: Springer; p. 171-193.

Frajman B, Eggens F, Oxelman B. 2009. Hybrid origins and homoploid reticulate evolution within Heliosperma (Sileneae, Caryophyllaceae)-A multigene phylogenetic approach with relative dating. Syst Biol. 58(3) 328-345.

Gaut BS, Morton BR, Mccaig BC, Clegg MT. 1996. Substitution rate comparisons between grasses and palms: Synonymous rate differences at the nuclear gene Adh parallel rate differences at the plastid gene rbcL. Proc Natl Acad Sci USA. 93(19):10274-10279.

Ghaffari SM. 2004. Cytotaxonomy of some species of Acanthophyllum (Caryophyllaceae) from Iran. Biologia (Bratislava). 59:53-60.

Gotelli NJ, Anderson MJ, Arita HT, Chao A, Colwell RK, Connolly SR, Currie DJ, Dunn RR, Graves GR, Green JL, et al. 2009. Patterns and causes of species richness: a general simulation model for macroecology. Ecol Lett. 12(9):873-886.

Harbaugh DT, Nepokroeff M, Rabeler RK, McNeill J, Zimmer EA, Wagner WL. 2010. A new lineage-based tribal classification of the family Caryophyllaceae. Int J Plant Sci. 171(2):185-198.

Jordan GJ, Macphail MK. 2003. A Middle-Late Eocene inflorescence of Caryophyllaceae from Tasmania, Australia. Am J Bot. 90(5):761-768.

Kay KM, Whittall JB, Hodges SA. 2006. A survey of nuclear ribosomal internal transcribed spacer substitution rates across angiosperms: an approximate molecular clock with life history effects. BMC Evol Biol. 6(1):36.

Kumar S, Stecher G, Tamura K. 2016. MEGA7: molecular evolutionary genetics analysis version 7.0 for bigger datasets. Mol Biol Evol. 33(7): 1870-1874.

López-Vinyallonga S, Mehregan I, Garcia-Jacas N, Tscherneva O, Susanna A, Kadereit JW. 2009. Phylogeny and evolution of the ArctiumCousinia complex (Compositae, Cardueae-Carduinae). Taxon. 58(1): 153-171.

Mahmoudi Shamsabad M, Vaezi J, Memariani F, Joharchi MR. 2012. A new species and a new record of Acanthophyllum C.A.Mey (Caryophyllaceae) from northeast of Iran. Iran J Bot. 92(1):20-63.
Mahmoudi Shamsabad M, Assadi M, Parducci L. 2018. Impact of climate change implies the northward shift in distribution of the IranoTuranian subalpine species complex Acanthophyllum squarrosum. J Asia-Pacific Biodivers. 11(4):566-572.

Mahmoudi Shamsabad M, Assadi M, Parducci L. 2019. Phylogeography and population genetics of Acanthophyllum squarrosum complex (Caryophyllaceae) in the Irano-Turanian region. Syst Biodivers. 17(4): 412-421.

Manafzadeh S, Salvo G, Conti E. 2014. A tale of migrations from east to west: the Irano-Turanian floristic region as a source of Mediterranean xerophytes. J Biogeogr. 41(2):366-379.

Manafzadeh S, Staedler YM, Conti E. 2017. Visions of the past and dreams of the future in the orient: the Irano-Turanian region from classical botany to evolutionary studies. Biol Rev. 92(3):1365-1388.

Meulenkamp JE, Sissingh W. 2003. Tertiary palaeogeography and tectonostratigraphic evolution of the Northern and Southern Peri-Tethys platforms and the intermediate domains of the African-Eurasian convergent plate boundary zone. Palaeogeogr Palaeoclimatol Palaeoecol. 196(1-2):209-228. (03)00319-5

Miller MA, Pfeiffer W, Schwartz T. 2010. Creating the CIPRES science gateway for inference of large phylogenetic trees. In: 2010 Gatew Comput Environ Work GCE 2010; Nov 14; New Orleans, LA, USA.

Mittermeier R, Robles GP, Hoffman M, Pilgrim J, Brooks T, Gill PR, Mittermeier CG, Lamoreux J. 2005. Hotspots revisited: Earth's biologically richest and most endangered terrestrial ecoregions. Washington (DC): Conservation International.

Moharrek F, Kazempour-Osaloo S, Assadi M, Feliner GN. 2017. Molecular phylogenetic evidence for a wide circumscription of a characteristic Irano-Turanian element: Acantholimon (Plumbaginaceae: Limonioideae). Bot J Linn Soc. 184(3):366-386.

Moharrek F, Sanmartín I, Kazempour-Osaloo S, Feliner GN. 2019. Morphological innovations and vast extensions of mountain habitats triggered rapid diversification within the species-rich Irano-Turanian genus Acantholimon (Plumbaginaceae). Front Genet. 9:698.

Moore BR, Höhna S, May MR, Rannala B, Huelsenbeck JP. 2016. Critically evaluating the theory and performance of Bayesian analysis of macroevolutionary mixtures. Proc Natl Acad Sci USA. 113(34):9569-9574.

Mouthereau F. 2011. Timing of uplift in the Zagros belt/Iranian plateau and accommodation of late Cenozoic Arabia-Eurasia convergence. Geol Mag. 148(5-6):726-738.

Noroozi J, Akhani H, Breckle SW. 2008. Biodiversity and phytogeography of the alpine flora of Iran. Biodivers Conserv. 17(3):493-521.

Noroozi J, Zare G, Sherafati M, Mahmoodi M, Moser D, Asgarpour Z, Schneeweiss GM. 2019. Patterns of endemism in Turkey, the meeting point of three global biodiversity hotspots, based on three diverse families of vascular plants. Front Ecol E. 7:159.

Pirani A, Zarre S, Pfeil BE, Bertrand YJK, Assadi M, Oxelman B. 2014. Molecular phylogeny of Acanthophyllum (Caryophyllaceae: Caryophylleae), with emphasis on infrageneric classification. Taxon. 63(3):592-607.

Pirani A, Zarre S, Rabeler R, Assadi M, Joharchi MR, Oxelman B. 2019. Systematic significance of seed morphology in Acanthophyllum (Caryophyllaceae: Tribe Caryophylleae) in Iran. Phytotaxa. 387(2): 105-118.

Plummer M, Best N, Cowles K, Vines K. 2006. CODA: Convergence Diagnosis and Output Analysis for MCMC. R News. 6:7-11.

Podlech D, Maassoumi AA. 2003. New species of Astragalus L. (Fabaceae) from Iran, mainly of sects. Incani and Malacothrix. Feddes Repert. 114(5-6):320-349.

Rabosky DL. 2014. Automatic detection of key innovations, rate shifts, and diversity-dependence on phylogenetic trees. PLoS One. 9(2): e89543.

Rabosky DL, Grundler M, Anderson C, Title P, Shi JJ, Brown JW, Huang H, Larson JG. 2014. BAMMtools: an R package for the analysis of evolutionary dynamics on phylogenetic trees. Methods Ecol Evol. 5(7): 701-707.

Rabosky DL, Mitchell JS, Chang J. 2017. Is BAMM flawed? Theoretical and practical concerns in the analysis of multi-rate diversification models. Syst Biol. 66(4):477-498. 
Rambaut A. 2018. FigTree v. 1.4.4. [accessed 2020 Jan 5]. http://tree.bio. ed.ac.uk/software/figtree/.

Rambaut A, Drummond AJ. 2013. Tracer v1.6. [accessed 2020 Jan 5]. http://Tree.Bio.Ed.Ac.Uk/Software/Tracer/.

Ranjbar M, Karamian R. 2003. Some remarks on the genus Astragalus sect. Incani in Iran. Bot J Linn Soc. 143(4):443-447.

Ree $\mathrm{RH}$, Smith SA. 2008. Maximum likelihood inference of geographic range evolution by dispersal, local extinction, and cladogenesis. Syst Biol. 57(1):4-14.

Rechinger KH, Schiman-Czeika H. 1974. Plumbaginaceae. In: Rechinger $\mathrm{KH}$, editor. Flora Iranica. Vol 108. Graz: Akademische Druck-u. p. $1-158$.

Schiman-Czeika H. 1988. Acanthophyllum. In: Rechinger KH, editor. Flora Iranica. Vol. 163. Graz: Akademische Druck- u. Verlagsanstalt. p. 253-329.

Takhtajan A. 1986. Floristic regions of the world. Berkeley: University of California Press.

Tsitrone A, Kirkpatrick M, Levin DA. 2003. A model for chloroplast capture. Evolution. 57(8):1776-1782.

van Dam JA. 2006. Geographic and temporal patterns in the late Neogene (12-3 Ma) aridification of Europe: the use of small mammals as paleoprecipitation proxies. Palaeogeogr Palaeoclimatol Palaeoecol. 238(1-4):190-218.

Vilhena DA, Antonelli A. 2015. A network approach for identifying and delimiting biogeographical regions. Nat Commun. 6(1):6848.

Wolfe KH, Li WH, Sharp PM. 1987. Rates of nucleotide substitution vary greatly among plant mitochondrial, chloroplast, and nuclear DNAs. Proc Natl Acad Sci USA. 84(24):9054-9058.

Yu Y, Harris AJ, Blair C, He X. 2015. RASP (Reconstruct Ancestral State in Phylogenies): A tool for historical biogeography. Mol Phylogenet $\mathrm{E}$. 87:46-49.

Yue B, Vick BA, Cai X, Hu J. 2010. Genetic mapping for the Rf1 (fertility restoration) gene in sunflower (Helianthus annuus L.) by SSR and TRAP markers. Plant Breed. 129(1):24-28.

Zachos JC, Dickens GR, Zeebe RE. 2008. An early Cenozoic perspective on greenhouse warming and carbon-cycle dynamics. Nature. 451(7176):279-283.

Zohary M. 1973. Geobotanical foundations of the Middle East. Vol. I and II. Stuttgart: Gustav Fischer.

Zohary D, Hopf M, Weiss E. 2012. Domestication of plants in the old world: the origin and spread of domesticated plants in Southwest Asia, Europe, and the Mediterranean Basin. Oxford: Oxford University Press. 